This is the penultimate (preprint/AOM) version; it does not reflect changes made in response to the comments of referees. The Version of Record of this manuscript has been published and is available in British Journal for the History of Philosophy,

https://www.tandfonline.com/doi/full/10.1080/09608788.2021.1895066.

\title{
Why Leibniz Should Have Agreed with Berkeley about Abstract Ideas
}

\author{
Stephen Puryear \\ North Carolina State University
}

\begin{abstract}
Leibniz claims that Berkeley "wrongly or at least pointlessly rejects abstract ideas." What he fails to realize, however, is that some of his own core views commit him to essentially the same stance. His belief that this is the best (and thus most harmonious) possible world, which itself stems from his Principle of Sufficient Reason, leads him to infer that mind and body must perfectly represent or "express" one another. In the case of abstract thoughts he admits that this can happen only in virtue of thinking some image that, being essentially a mental copy of a brain state, expresses (and is expressed by) that state. But here he faces a problem. In order for a thought to be genuinely abstract, its representational content must differ from that of any mental image, since the latter can represent only something particular. In that case, however, an exact correspondence between the accompanying mental image and the brain state would not suffice to establish a perfect harmony between mind and body. Even on Leibniz's own principles, then, it appears that Berkeley was right to dismiss abstract ideas.
\end{abstract}

Keywords: Leibniz, Berkeley, Abstraction, Abstract Ideas, Abstract Thoughts

\section{Introduction}

Toward the end of his life, probably in the year 1715, Leibniz acquired a copy of George Berkeley's recently published masterpiece, A Treatise Concerning the Principles of Human Knowledge. ${ }^{1}$ On the last page of his copy, Leibniz penned

1 This copy resides today in the Gottfried Wilhelm Leibniz Bibliothek in Hannover and may be accessed online at http://digitalesammlungen.gwlb.de/resolve?PPN=797331344. 
a brief assessment of the work. He starts on a positive note-"Much here that is right and close to my view"-but goes on to list a number of points on which he disagrees with the Irish philosopher. ${ }^{2}$ One of these points will be my focus here: namely his objection that Berkeley "wrongly or at least pointlessly rejects abstract ideas." I will argue that some of Leibniz's own core principles and views commit him to rejecting abstract ideas and thus that, instead of taking issue with Berkeley on this point, he should have concurred.

The body of the paper comprises four sections. In the first (§2), I briefly sketch the broad outlines of Berkeley's critique of abstract ideas in the Principles, which appears in the Introduction ( $\S \S 6-25)$. In the next two sections I turn to Leibniz's account of abstract thought, focusing first on how his doctrine of mindbody parallelism shapes that account ( $\S 3$ ) and second on the critical role played by the faculty of imagination ( $\$ 4)$. With all this in place, I then prosecute the case for my critical point ( $\$ 5)$.

\section{Berkeley's Rejection of Abstract Ideas}

In the Introduction to his Principles, Berkeley defines an abstract idea as one which the mind frames to itself by the process of abstraction, that is, of "singling out" and "considering apart" some quality, mode, or being that does not exist on its own in reality. An example of the first sort would be the color of a particular body, say, the redness of a certain uniformly colored ball. To conceive this redness apart from the other qualities of the ball, such as its shape and weight, which the redness cannot exist apart from in reality, would be to frame an abstract idea. Similarly, if one were to "consider apart" that which the many colors one has observed have uniquely in common, the result would be an abstract idea of color itself-that is, not of any particular color but of color in the abstract. Or, to give an example of a being rather than a quality or mode, if one were to abstract, from the many ideas of particular balls that one has, what they have uniquely in common, the result would be an abstract idea of ball, which is not an idea of any particular ball but of ball in the abstract.

According to Berkeley we humans aren't actually able to abstract in these ways. When we reflect on our mental operations, we find ourselves with a faculty of imagination, by which we represent to ourselves the various particular things

2 Translations of parts of this note are my own, from the Latin at Robinet (1983: 218); cf. AG 307. 
that we have perceived, and by which we can compound and divide these ideas in various ways. But all the ideas that can be apprehended or produced in this way are particular, determinate ideas. We cannot imagine color in the abstract or ball in the abstract but only a particular color or a particular ball. And we find within ourselves no other faculty for framing ideas to ourselves than the imagination. ${ }^{3}$ So all of our ideas are particular, not abstract. As Berkeley declares,

I own myself able to abstract in one sense, as when I consider some particular parts or qualities separated from others, with which though they are united in some object, yet, it is possible they may really exist without them. But I deny that I can abstract one from another, or conceive separately, those qualities which it is impossible should exist so separated; or that I can frame a general notion by abstracting from particulars in the manner aforesaid. Which two last are the proper acceptations of abstraction. ( $\$ 10)$

It might be countered that we do find ourselves with an ability to frame abstract ideas; after all, nothing could be easier than to think of notions such as color, ball, man, animal, being, and a thousand other abstractions. According to Berkeley, however, this thought is mistaken. When we think of something like man, what we are in fact doing is picturing to ourselves something particular, such as the word 'man' or perhaps a prototypical man, which we then take to stand for many instances of men. In other words, we make some particular idea serve for us as a general idea. Berkeley describes this as a particular idea becoming general: "I believe we shall acknowledge, that an idea, which considered in itself is particular, becomes general, by being made to represent or stand for all other particular ideas of the same sort" (§12). But, to be sure, this general idea is still particular and determinate, not abstract. What Berkeley denies is not the existence of general ideas but of abstract general ideas (§12).

Much more could be said about Berkeley's critique of abstract ideas, but for our purposes the essential points are now on the table. They are, first, that all our ideas, being images in the mind, are particular, not abstract; and second, that a particular idea may be made to represent or stand for many things at once, in which case it becomes general, while remaining a particular idea. Let us now turn to Leibniz.

${ }^{3}$ Here I follow Leibniz in taking Berkeley's view to be that all ideas are images. For a contrasting perspective on this and on Berkeley's case against abstraction, see Flage (1986). 


\section{Leibniz on Abstract Thoughts and Mind-Body Parallelism}

When Leibniz speaks of abstract cognition, he typically focuses on thoughts rather than ideas. In his terminology a thought is an occurrent mental state, whereas an idea is an enduring mental content. More precisely, an idea is the content (or "immediate internal object") of a thought, which is present in the mind even when we aren't thinking of it. ${ }^{4}$ For instance, my thought of the number $\pi$ has for its content the idea of $\pi$. To think of $\pi$ just is to bring that idea before one's mind. So we can see that abstract thoughts and abstract ideas are closely related: an abstract thought is simply a thought the content (or "immediate object") of which consists in at least one abstract idea. Abstract thoughts thus involve and presuppose abstract ideas, and to cognize an abstract idea is just to have an abstract thought.

Leibniz appears to take the existence of abstract thoughts as a given. To my knowledge, he never argues for their existence and in fact the only place where he even so much as directly addresses the question of their existence is his comment about Berkeley. When he does discuss abstract thoughts, it is typically to make a point that is important to him because of his doctrine of the perfect harmony (or parallelism) between mind and body. This is the point that there can be no abstract thought in the soul without a corresponding occurrence in the body, and specifically the brain.

For the sake of brevity, I will here refer to Leibniz's doctrine of the perfect harmony of mind and body as Harmony. Here is one example of a passage, from the essay Considerations on the Doctrine of a Single Universal Spirit (1702), in which he propounds the doctrine and connects it with abstract thought:

\footnotetext{
${ }^{4}$ See NE 109 for the description of an idea as an "immediate internal object" of thought (and as "an expression of the nature or qualities of things"). For similar characterizations, see DM 26; Leibniz to Thomas Burnett, 11 June 1695, GP 3:162; GP 3:240-41; Sample of Reflections on the First Book of the Essay of [Human] Understanding, 1698, A 6.4:11-12/GP 5:21. Leibniz also construes ideas as dispositions to think: see What Is an Idea?, ca. 1677, A 6.4:1370-71/L 207-8; NE 52, 106; cf. NE 86-87. For helpful discussion of this latter conception, see Jolley (1990: 132-39). In my view Leibniz intends these accounts of ideas to be compatible: the enduring internal object of a thought, he thinks, just is what disposes us to think that thought when the occasion presents itself.
} 
I find that [...] there is never any abstract thought, which is not accompanied by some material images or traces, and I have established a perfect parallelism between what happens in the soul and what happens in matter, having shown that the soul with its functions is something distinct from matter, but that nonetheless it is always accompanied by material organs, and also that the functions of the soul are always accompanied by the functions of organs, which must correspond to them, and that this is reciprocal and always will be. (GP 6:533/L 556; see also NE 77; GP 4:559/WF 112)

As Leibniz indicates here, he holds that the soul is something distinct from matter: it is an immaterial substance. Yet he also believes that the soul always runs perfectly in parallel with the material organs of the body, in the sense that the functions of the one always correspond to those of the other, even in the case of the most abstract thoughts.

Leibniz affirms Harmony most fundamentally because he sees it as an implication of one of his foundational principles: the Principle of Sufficient Reason (PSR). This is of course the principle that there is always a sufficient reason why things are one way rather than another (M 32). According to Leibniz, this principle entails that God must have created the best of all possible worlds. ${ }^{5}$ This is because there could be no sufficient reason for creating an inferior world. Were God to create such a world, the question would always remain: Why not create a better one? Only if God created the best of the possible worlds would there be a sufficient reason for his choice. So the PSR requires that he create the best of all possible worlds. ${ }^{6}$ But Leibniz also holds that part of what it means to be the best is to be the most harmonious, and so it further follows from the PSR that this world exhibits the greatest possible amount of harmony. This in turn means that every substance, including every mind or soul, must perfectly harmonize with all the others, each representing the same world from its own unique point of view. But it also means that every substance, including every

${ }^{5}$ Leibniz refers to this principle (i.e., that God must have created the best of all possible worlds) variously as the Principle of Perfection (A 6.4:1445/AG 19; A 6.4:1448/AG 22; GP 7:272/L 478) or the Principle of the Best (GP 6:44, 386; M 48; GP 7:390).

${ }^{6}$ For a similar reflection in the context of Leibniz's rejection of empty space, see the appendix to his fourth letter to Samuel Clarke (GP 7:378), where he argues that there is no sufficient reason for choosing any ratio of matter to vacuum other than 1:0. 
mind or soul, is at all times perfectly in harmony with its body. So whenever something happens in the mind, something corresponding to this must happen in the body, and vice versa. Otherwise this disharmony would detract from the perfection of the world, thus violating the PSR.

Returning to Harmony itself, we have seen that on Leibniz's view an abstract thought must be accompanied by certain "material traces", i.e., brain states. The talk of "accompanying" here does however somewhat understate the matter. In point of fact, Leibniz holds that in order for Harmony to be satisfied, the abstract thought and the accompanying brain state must be not merely correlated but naturally and thus intelligibly connected. The reason for this comes back to the PSR. The connection between mental and bodily states is one established by God. But if it were not intelligible, then it would be arbitrary. And God cannot do anything arbitrarily, because that would violate the PSR. The connection must therefore be an intelligible one.

Leibniz brings this general point out most clearly in another context: that of our confused perceptions of sensible qualities such as color. Many philosophers in his day supposed these sensations to be only arbitrarily connected with their mechanical causes. ${ }^{7}$ But Leibniz strenuously objects to this view. As he has it, the connection between a sensation and its cause must rather be an intelligible one, because otherwise it would follow that the author of these connections-i.e., God-acted arbitrarily and thus without a sufficient reason, in violation of the PSR. ${ }^{8}$

In fact, Leibniz takes this a step further: he holds that an intelligible connection between sensation and cause must take the form of a resemblance. As he explains in the New Essays, where Locke's view comes under fire:

It must not be supposed that these ideas such as those of color and pain are arbitrary and without natural relation or connection with their causes: it is not the way of God to act with so little order and reason. I would say rather that there is a kind of resemblance, not entire and so to speak in terminis, but expressive, or a relation of order, just as an ellipse and even a parabola or hyperbola resemble in some way the circle of which they

7 See, e.g., Locke, who attributes the connection to "the arbitrary Will and good Pleasure of the Wise Architect" (Essay Concerning Human Understanding, IV, iii, 29; see also II, viii, 13; IV, iii, 6).

8 The sense of 'cause' here is of course what Leibniz calls "ideal causation" (or more typically "ideal action"). On this kind of causation, see Puryear (2010), Jorati (2017: 47-52), and Jorati (2020: 255-56). 
are the projection on the plane, since there is a certain exact and natural relationship between that which is projected and the projection, which is made from it, each point of the one corresponding according to a certain relation to each point of the other. (NE 131; see also GP 4:574-577/WF 140-142; NE 132-133, 403-404; GP 6:326-327)

A sensation or idea comes to be naturally rather than arbitrarily connected with its cause, Leibniz claims, by resembling it. But this resemblance is "not entire and so to speak in terminis" but is rather an "expressive" resemblance, or in other words, a "relation of order". The precise significance of the term 'in terminis' here is unclear, but the contrast appears to be between resemblance that is complete-a resemblance in every respect-and a resemblance specifically with respect to structure, one that consists in the parts or constituents of the one "corresponding according to a certain relation to each point of the other." The point is that, though a sensation of color or some other sensible quality does not perfectly resemble its mechanical causes-does not, for example, resemble them superficially or in appearance-it does nonetheless have an implicit structure that resembles or is isomorphic to the structure of its causes. ${ }^{10}$ Leibniz calls this an "expressive" resemblance because on his view, expression consists in precisely this kind of structural correspondence, or as he puts it, in the existence of "a certain constant relational law, by which particulars in the one can be referred to corresponding particulars in the other" (C 15/MP 176-77). ${ }^{11}$ So we could also

9 See also GP 4:575/WF 141: "Someone will perhaps say that the sensation of heat does not resemble the motion: yes, without doubt, it does not resemble a sensible motion, such as that of a carriage wheel; but it does resemble the assemblage of small motions in the fire and in the organs, which are its cause; or rather it is only their representation."

10 On Leibniz's view, our sensations of such qualities, despite appearing simple, are in fact composed of many smaller perceptions, which are the perceptions of the individual mechanical qualities which together cause the sensation. The sensation thus has a hidden complexity or structure in virtue of which it corresponds to the structure of its cause. On this, see Pearce (2016: 2-5).

${ }^{11}$ In the essay What is an Idea? (ca. 1677), Leibniz defines expression as a certain "correspondence" or "analogy" between the relations (habitudines) of the expression and those of the thing expressed, one which allows us to "pass from a consideration of the relations in the expression to a knowledge of the corresponding properties of the thing expressed" (A 6.4:1370/L 207). See also Leibniz to Arnauld, 9 October 1687, A 2.2:240/LA 240-41: "One thing expresses another (in my language) when there is a constant and ordered relation between what can be said of the one and of the other." 
put the point this way: our sensations and their causes must mutually express (or represent) each other; only in this way could the actions of the author of these correlations fully accord with the PSR. ${ }^{12}$

Returning now to the case of abstract thoughts, we can see that by the same token such thoughts must bear a natural rather than an arbitrary relation to the corresponding brain states; that is, they must resemble, or more precisely must express or represent, those brain states (and vice versa). And this is precisely what Leibniz holds. As he writes to the Electress Sophie, "the thoughts of the soul [...] must represent what happens in the body" (Leibniz to Electress Sophie, 30 November 1701, A 1.20:85). Further, he is clear that the body represents everything in the soul: "there is nothing in the soul which is not also expressed in the organs of the body" (Leibniz to Jaquelot, 9 February 1704, GP 3:465/WF 176; cf. NE 117). And abstract thoughts are always represented specifically by traces in the brain, as he explains in a draft letter to the Electress' daughter:

I establish an exact relation between soul and body, and I believe that

even the more abstract thoughts are represented by some traces in the brain, according to the manner that I have explained elsewhere [...].

(Leibniz to Queen Sophie Charlotte [draft], 1702, A 1.21:718)

Abstract thoughts and the corresponding brain states thus always exactly represent one another.

\section{Leibniz on Abstract Thoughts and the Imagination}

At this point we may wonder how an abstract thought could stand in a relationship of mutual expression with a brain state. After all, the former represents something incomplete and indeterminate. If I think of man, for instance, my thought (supposedly) represents manhood-not any particular man but man in the abstract. Like any physical state or object, however, a brain state would seem capable of representing only something determinate and particular. Consider, for instance, a picture of my favorite mug. There is no

12 This is not to deny that there can in a sense be arbitrary connections in the world. As we will see in $\S 4$, Leibniz himself characterizes the connection between an abstract thought and its associated symbols as an arbitrary one. It should be noted, however, that from his perspective these arbitrary connections could only be established by imperfectly rational beings, not by a perfectly rational one, and furthermore must be arbitrary not absolutely, or from the point of view of God, but only relative to the knowledge of finite minds. 
difficulty in understanding how that picture could express the mug, in Leibniz's sense of 'express': we need only suppose that the parts of the picture-e.g., the bits of ink it comprises-form a structure that corresponds to the structure formed by the parts of the mug. In contrast, however, it's difficult to see how that picture could express something abstract such as the number seven or man. To be sure, one could stipulate that something physical stands for some abstract thing. But that wouldn't be what Leibniz calls expression, which requires a structural correspondence between the parts or constituents of the one and those of the other. Besides, that would be an arbitrary relation, not the kind of intelligible relation that he requires between mental states and bodily states. Contrary to what Leibniz suggests, then, it does not seem that abstract thoughts and brain states could perfectly express one another.

To see how Leibniz would overcome this difficulty, we need to introduce an important wrinkle in his account. It concerns the role played by the imagination in abstract cognition. According to him, when we think some abstract thought, we must also be engaging the imagination, i.e., thinking some image, some sensible content; and this imagining is what makes it possible for Harmony to obtain. As Leibniz explains in some unpublished comments on Pierre Bayle's Historical and Critical Dictionary (1697),

Although humans reason about things that are abstract and that surpass the imagination, there are still signs in the imagination which correspond to these things, such as letters and symbols [caracteres]. There is never an act of understanding so pure that it is not accompanied by some imagination. Thus there is always something mechanical in the body which exactly corresponds to the train of thoughts, which is in a person's mind, insofar as they involve imagination. (GP 4:541/WF 100)

Leibniz tells us here that abstract thoughts surpass the imagination; they are not merely images, at least not as such. ${ }^{13}$ But there are nonetheless signs or characters in the imagination that correspond to these abstract thoughts and in fact he goes on to say that our thoughts "exactly correspond" to our bodily states "insofar as they involve the imagination" (my emphasis). So he seems to acknowledge that abstract thoughts cannot in themselves expressively resemble brain states. But, he seems to think, they can do so in virtue of

${ }^{13}$ See also Letter Touching on What Is Independent of the Senses and of Matter, 1702, A 1.21:340/AG 188. 
corresponding in some way to mental images that, being particular, do "exactly correspond" to the relevant brain states.

Leibniz makes essentially the same point in the contemporaneous New Essays:

[T]hrough an admirable economy of nature we cannot have abstract thoughts which have no need of something sensible, even if only characters such as the sounds and shapes of letters; though there is no necessary connection between such arbitrary characters and such thoughts. And if these sensible traces were not required, the harmony pre-established between the soul and the body, which I shall later have an opportunity to talk to you about more fully, would not obtain. (NE 77) Here Leibniz says that abstract thoughts have need of "arbitrary characters" and that there is no necessary connection between the two. ${ }^{14}$ These characters are also said to be "something sensible" such as "the sounds and shapes of letters." He doesn't make this as clear as he could have, but these characters are evidently images in the mind, not physical states in the brain. One reason for thinking this is that he says the characters are arbitrary, bearing no "necessary connection" to the thoughts, whereas we have seen that in his view such thoughts must relate intelligibly, i.e., non-arbitrarily, to the corresponding brain states. So the point is that if abstract thoughts were not accompanied by sensible traces in the imagination, then Harmony would be false. ${ }^{15}$

What Leibniz appears to be getting at is this. Brain states, as we have said, are complete, determinate, and particular (which really come to the same thing). More to the point, any brain state that correlates with an entire thought has an immensely complex structure and thus an immensely complex representational content. (Leibniz holds that brain states have an infinitely complex structure, but the point holds even if that's false.) Thus the only sort of thing which could perfectly express such a state is another thing with an immensely complex structure. But the only thing in the mind which fits this bill would be a mental image, which is (in effect) just a copy of a brain state. It isn't hard to see, at least

\footnotetext{
${ }^{14}$ See also On Forms, or the Attributes of God, 1676, A 6.3:514/L 160.

${ }^{15}$ For other texts in which Leibniz affirms that abstract thoughts require some act of imagination, see GP 3:466/WF 177; GP 4:541/WF 100; GP 4:559/WF 112; GP 4:563/WF 117; GP 4:574/WF 140; GP 6:626/AG 226; cf. A 1.21:344/AG 191. For helpful further discussion of the role of imagination in Leibniz's account of abstract cognition, see Jorati (2020: 259-67). See also Sepper (2005: 329-34) for further background on Leibniz's conception of imagination.
} 
in general terms, how these two things-the mental image and the brain statecould express one another, just as a picture of my favorite mug can express the mug. Perhaps the expression here is not "entire or so to speak in terminus," as Leibniz says of our sensations of sensible qualities and their mechanical causes. But we can at least see how an expressive resemblance might obtain in this case: namely, we can understand the image in the imagination as consisting of vastly many smaller images that relate to one another in ways that correspond to the ways that the minute brain traces relate to one another. In this way the mental images make possible a precise mutual expression between mind and body.

The basic picture, then, is this. Whenever a mind thinks an abstract thought, it also thinks some image, which is arbitrarily connected to the abstract thought. That image in turn perfectly expresses and is thus intelligibly related to a concurrent brain state. So even in the case of abstract thoughts, there is a perfect correspondence between what happens in the mind and what happens in the body.

So described, this might not seem to deliver exactly what Leibniz wants. It does establish an intelligible connection between the mental image accompanying an abstract thought and the corresponding brain state. But he claims something more: he claims that every mental state, including abstract thoughts, must naturally and intelligibly relate to some bodily state. And for good reason: for were this not the case, then there would not be a perfect harmony between mind and body. Yet on the picture he offers us, abstract thoughts correspond to brain states only via their connection with mental images, and this latter connection is arbitrary. So the connection between the abstract thought and the corresponding brain state is likewise an arbitrary one, contrary to what is required for the truth of Harmony.

I would like to speculate on how Leibniz might address this problem. In one text from the New Essays, he speaks of the sensible contents in the imagination as the "matter for reflections": "The senses provide us with the matter for reflections, and we could not think even of thought if we did not think of some other thing, that is, of particularities that the senses provide" (NE 212; cf. GP $6: 532 / L 556$ ). I would suggest that the expression "matter for reflections" might be taken to indicate that he is thinking about abstract thoughts in hylomorphic terms: namely, that he's thinking of the abstract thought as having both a material component, i.e., the mental image, and a formal component in virtue of which the composite of the two somehow comes to have an abstract 
representational content. ${ }^{16}$ If this were right, then his view, properly stated, would be that abstract thoughts do in a sense express brain states, namely with respect to their matter, even though in another sense, with respect to their form, they would express something abstract and would be only arbitrarily connected with these brain states. This proposal would seem to harmonize all of Leibniz's claims. Abstract thoughts would in a sense express brain states, yet they would do so only with respect to their material component. So mental images would be necessary for the truth of Harmony, just as Leibniz claims. At the same time, though, abstract thoughts would not merely be mental images, at least not as such; they would in a sense "surpass the imagination" (GP 4:541/WF 100).

\section{The Problem for Leibniz's Account}

When we think an abstract thought, Leibniz claims, there is always at the same time an imagining, i.e., the thought of an image, which makes possible a perfect harmony between mind and body. Now these are evidently meant to be distinct mental acts; for they do after all have different representational contents. A mental image is a particularized representation; i.e., it represents some particular entity, such as a particular horse. Its structure is such as to represent that particular horse in a way that it doesn't represent other horses, which always differ in some qualitative respects. An abstract idea, in contrast, does not fully represent any particular entity in this way. The abstract idea horse does not represent some particular horse to the exclusion of others. Rather, it represents all horses insofar as they are horses; it represents just their horseness-horseness in the abstract-not the particular features that distinguish one horse from another. The representational content of the abstract idea must therefore differ from that of any mental image.

Leibniz appears to be well aware of this. For he says that when we think of something abstract, we must "think of some other thing, that is, of particularities [particularités] that the senses provide" (NE 212). Likewise, he says that abstract thoughts "surpass the imagination" (GP 4:541/WF 100)-presumably by representing things that the imagination cannot represent. But it is precisely this fact, i.e., that abstract thoughts differ from mental images with respect to their representational content, that poses a problem for Leibniz's view.

${ }^{16}$ Compare Jorati's suggestion that, for Leibniz, abstract thoughts have both an abstract content and a sensible vehicle (2020: 263-64). 
Here's why. Leibniz insists that every abstract thought must involve thinking an image because otherwise mind and body would not be perfectly in harmony. Images are needed because they, unlike abstract thoughts themselves, can intelligibly relate to traces in the brain. The abstract thought involves (or is accompanied by) an image that itself corresponds naturally to a certain brain state, so the abstract thought also in a way corresponds to the brain state. But if the representational content of the abstract thought isn't exhausted by the representational content of the image, then there isn't really a perfect mindbody harmony. To illustrate, consider the case in which I think of horse; that is, I have a thought the content of which is the idea horse. And suppose that the image I think of when I'm having this thought is the shape 'horse'. Now compare that with a case in which I merely think of that shape, but not of horse, i.e., a case in which I merely think the word but not what it represents. In these two cases, what I am imagining is the same. So the corresponding brain states must be the same as well. But in the one case, I'm also thinking of horse, the abstract content, and in the other I'm not. So we have a difference in the mind, but no corresponding difference in the brain (or body). Hence, if the representational content of the (putative) abstract thought goes beyond the representational content of the image, then Harmony fails. And likewise, since Harmony is entailed by the PSR, the latter fails too.

One might attempt to defend Leibniz against this charge by challenging the assumption that a mental image must represent some particular entity rather than having an abstract representational content. There is some reason to think that he himself might have denied this premise. In the letter to Sophie Charlotte that he titled Letter Touching on What Is Independent of the Senses and of Matter (1702), Leibniz claims that the imagination contains not only the clear but confused notions of the individual senses but the clear and distinct notions of the common sense, such as the ideas of number and shape, which he describes as "the objects of the mathematical sciences, namely arithmetic and geometry" (A 1.21:339/AG 187; see also GP 6:488, 493). Now the import of this would appear to be that the imagination contains not only particular images that it receives from the senses (or constructs purely from sensory materials) but also abstract representations such as those of number and shape. ${ }^{17}$ In that case, however, Leibniz could perhaps say that the latter images represent something

17 For a fuller development of this reading, see Leduc (2014: 58-67) and especially Leduc (forthcoming). 
abstract while at the same time expressively resembling brain states, thus making a perfect harmony possible even when the mind thinks abstract thoughts.

I'm not convinced that this is the right reading of the passage from the letter to Sophie Charlotte. But even if it is, the important point is that it doesn't really improve Leibniz's situation with respect to our problem. In simplest terms, it tells us that abstract ideas are to be found in the imagination rather than the intellect; they are in fact images. But the problem is that this casts no light on how such an abstract content could expressively resemble a brain state. Merely labelling the abstract mental content an image does nothing to explain how Harmony could obtain in the case of abstract cognition.

Another reply that one might offer on Leibniz's behalf is that my objection mischaracterizes his position. Despite what he sometimes seems to say, his view is properly speaking that the PSR requires not that God create a world with perfect harmony, but that God create the most harmonious of the worlds available to him. Now if there were possible worlds in which abstract thoughts expressively resembled brain states, then perhaps the PSR would require that God create one of those worlds. But, the reply continues, the fact is that it isn't actually possible for an abstract idea to expressively resemble any brain state, for the very reason already given. Not even God could create such a world. Thus, the fact that the world isn't like that doesn't violate the PSR. That principle requires that God create the best and thus the most harmonious of all possible worlds. And since it isn't possible for abstract ideas to intelligibly relate to brain states, it follows that the best God could do with respect to maximizing harmony is to create a world like the one Leibniz describes, i.e., one in which every abstract thought is at least connected with something that intelligibly relates to a brain state. Thus, Harmony, properly understood, does obtain, even though this world is not perfectly or absolutely harmonious.

The problem with this reply is that, even if it's true that there is no possible world in which abstract thoughts intelligibly relate to brain states, there are possible worlds that exhibit greater harmony than the sort of world that Leibniz thinks God has created: namely the kind of world that Berkeley thinks God has created, i.e., a world with only particular ideas, with something like Berkeley's general ideas taking the place of Leibniz's abstract ideas. In that sort of world, there really would be a perfect harmony between mind and body: every mental state would expressively resemble and thus intelligibly relate to a corresponding 
brain state. Thus, the PSR seems to entail that God would create that sort of world rather than a world with abstract thoughts.

It's worth remembering that in other areas, Leibniz himself uses failures of the PSR to rule out certain views. These include the views that space and time are absolute, that sensible qualities are only arbitrarily connected with their causes, that matter thinks, that matter is active, and that there are attractive forces in nature. According to him, these views all involve violations of the PSR and thus can safely be dismissed. But then the same point applies to the case of abstract thought. Those thoughts have a representational content which

precludes any intelligible connection with a brain state. So at best they can be accompanied by something that intelligibly connects with such states. But the abstract thoughts themselves still don't intelligibly relate to the brain states. In keeping with his rejection of such things as thinking matter and attractive forces, then, it seems that Leibniz should have also rejected the existence of abstract thoughts and ideas, just as Berkeley does.

\section{Conclusion}

Appealing to principles such as the PSR, Leibniz firmly embraces the view that this is the best and thus most harmonious of all possible worlds. He even goes so far as to claim that there is a perfect harmony between the states of one's mind and those of one's body. Yet this characteristically Leibnizian stance clashes with another aspect of his thought: his acceptance of abstract thoughts and ideas. In order for abstract thoughts to harmonize with brain states, they would have to bear some intelligible connection to one another; and it is difficult to see what this could be if not what Leibniz takes it to be, i.e., an expressive resemblance. For the reasons I have adduced here, however, no abstract thought could expressively resemble a brain state. At best, abstract thoughts could be associated with some other mental states-i.e., imaginings-that do succeed in expressively resembling brain states. But a failure of harmony remains. Given his commitment to principles such as the PSR, then, it follows that Leibniz should not have criticized Berkeley on this point, saying that he "wrongly or at least pointlessly rejects abstract ideas"; rather he should have joined Berkeley in rejecting abstract ideas and in holding instead that what we ordinarily take to be abstract ideas are in fact just general (though particular) ideas, that is, particular ideas that we make to stand for many particular things. Likewise, he should not have objected that the Irishman "restricts ideas to 
images" (AG 307); for his own principles commit him to precisely such an imagistic and particularist theory of ideas.

Had Leibniz seen fit to reject abstract ideas, this clearly would have had wider implications for his philosophy. It would be too much to attempt a full account of these implications here, so I won't. ${ }^{18}$ But I would like to conclude by briefly noting one of the more definite implications. It concerns his attempt to accommodate the widespread belief that many of our ideas come to us through the senses. Leibniz's consistent position is that all ideas are strictly speaking innate. ${ }^{19}$ Yet he qualifies this by saying that in a sense it's quite true that some of our ideas have a sensory (and thus external) origin-in short, are adventitious. Thus in $\$ 27$ of the Discourse on Metaphysics, he comments on Aristotle's likening of the soul to a blank slate (tabula rasa) and the Scholastic-Aristotelian dictum that nothing resides in the understanding which was not first in the senses, saying that these expressions "can be given a good sense, a sense according to which they have nothing false in them, just as I have already noted how one can truly say that particular substances act on one another" (DM 27). Similarly, he remarks in the New Essays that the accepted view according to which some of our ideas come from without is "sound and justifiable" (NE 74).

This is no place for a deep dive into Leibniz's theory of adventitious ideas, but the gist of the view can be stated briefly. Namely, he holds that an idea can be considered adventitious just in case (and because) the thinking of that idea is "ideally caused" by something external to the mind that thinks it, where to cause something ideally is to be the reason which moves God to create it (DM 27). ${ }^{20}$ Thus if a mind thinks a certain idea at a certain time, and the reason God created a mind with that thought at that time is to be found in another created substance, then that other substance is the ideal cause of the mind's thought

${ }^{18}$ One implication would concern his philosophy of mathematics. Clearly he could no longer suppose that our ideas of mathematical objects such as numbers and geometrical figures are abstract, i.e., are ideas of abstract objects. Perhaps he would instead need to say that our ideas of these mathematical objects, being ideas of relations, are in fact particular ideas that we make to stand for other particular ideas (or things). I won't develop that thought any further here, or speculate on what changes it might require with respect to Leibniz's first-order mathematical views, but the reader may find it helpful to consider how Berkeley himself develops his non-abstractionist philosophy of mathematics (on which see Jesseph 1993).

${ }^{19}$ See DM 26; NE 74, 110.

20 [Suppressed] 
and the idea which is the thought's object can in this sense be considered to have an external origin.

To come now to the point, Leibniz's stated view is that some ideas, namely sensory ideas such as my idea of the color of my favorite mug, do have such an external ideal cause and are thus in a sense adventitious, while other ideas, namely intellectual ideas such as those of being and truth, are in all senses innate. But were he to admit that there are no abstract ideas, and thus that all ideas are imaginative, as his commitment to Harmony seems to require, then he would have to admit that all ideas are really sensory ideas and hence that all ideas, even if strictly speaking innate, are in the specified sense adventitious. In other words, he would have to admit that it is quite true in a sense that all ideas have an external source and thus a sensory origin. And this would of course constitute a significant concession to the empiricist.

\section{Abbreviations}

A Sämtliche Schriften und Briefe, Deutsche Akademie der Wissenschaften (ed.). Darmstadt und Berlin: Akademie-Verlag, 1923-. Cited by series, volume, and page number.

AG G.W. Leibniz: Philosophical Essays, Roger Ariew and Daniel Garber (eds. and trans.). Indianapolis: Hackett, 1989.

C G. W. Leibniz: Opuscules et fragments inédits, L. Couturat (ed.). Hildesheim: George Olms, 1903.

DM Discourse on Metaphysics. Cited by section number.

GP Die philosophischen Schriften von Gottfried Wilhelm Leibniz, C. I. Gerhardt (ed.). Berlin: Weidmannsche Buchhandlung, 1875-90. Cited by volume and page number.

L Gottfried Wilhelm Leibniz: Philosophical Papers and Letters, Leroy Loemker (ed.). Boston: Kluwer, 1989.

LA The Leibniz-Arnauld Correspondence, Stephen Voss (ed. and trans.). New Haven: Yale, 2001.

M Monadology. Cited by section number.

MP Leibniz: Philosophical Writings, M. Morris and G. H. R. Parkinson (eds. and trans.). London: J. M. Dent, 1973.

NE New Essays on Human Understanding. Cited by page number from A 6.6. 
WF Leibniz's 'New System' and Associated Contemporary Texts, R. S. Woolhouse and Richard Francks (eds. and trans.). Oxford: Oxford University Press, 1997.

\section{Bibliography}

Flage, Daniel E. 1986. "Berkeley on Abstraction," Journal of the History of Philosophy 24(4): 483-501.

Jesseph, Douglas. 1993. Berkeley's Philosophy of Mathematics. Chicago: University of Chicago Press.

Jolley, Nicholas. 1990. The Light of the Soul: Theories of Ideas in Leibniz, Malebranche, and Descartes. Oxford: Clarendon Press.

Jorati, Julia. 2017. Leibniz on Causation and Agency. New York: Cambridge University Press.

Jorati, Julia. 2020. "Embodied Cognition Without Causal Interaction in Leibniz." In Dominik Perler \& Sebastian Bender (eds.), Causation and Cognition in Early Modern Philosophy. New York: Routledge, 252-273.

Leduc, Christian. 2014. "The Epistemological Functions of Symbolization in Leibniz's Universal Characteristic." Foundations of Science 19: 53-68.

Leduc, Christian. Forthcoming. "Imagination and Reason in Leibniz." Studies in History and Philosophy of Science.

Pearce, Kenneth L. 2016. "Leibniz on the Veridicality of Body Perceptions," Philosophers' Imprint 16(5): 1-17.

Puryear, Stephen. 2010. "Monadic Interaction." British Journal for the History of Philosophy 18 (5):763-796.

Robinet, André. 1983. "Leibniz: Lecture du 'Treatise' de Berkeley." Les Études philosophiques 2: 217-223.

Sepper, Dennis L. 2005. "Spinoza, Leibniz, and the Rationalist Reconceptions of Imagination." In Alan Nelson (ed.), A Companion to Rationalism. Malden, MA: Blackwell, 322-42. 